Jurnal Indonesia Sosial Teknologi: p-ISSN: 2723 - 6609

e-ISSN : 2548-1398

Vol. 1, No. 3 Oktober 2020

\title{
RANCANGAN PERBAIKAN STASIUN KERJA DI PT KARSA WIJAYA PRATAMA DENGAN MENGGUNAKAN METODE PLIBEL CHECKLIST DAN QEC (QUICK EXPOSURE CHECK)
}

\author{
Putri Pertiwi dan Zeny Fatimah Hunusalela \\ Universitas Indraprasta PGRI Jakarta \\ Email : putri.prtw13@gmail.com dan zeny.fh86@gmail.com
}

\begin{abstract}
Abstrac
PT Karsa Wijaya Pratama is an industry engaged in the automotive sector, several activities are carried out using manual production machines. Based on the observation of problems that arise in the company that cause risks to work due to the worker's body posture that is not in accordance with the standards, the purpose of this research is to ensure workers can work properly so as not to injure the muscles in the long or short term. The research begins by identifying problems and assessing work posture with the PLIBEL Checklist and Quick Exposure Check (QEC) questionnaire. Based on the results of the overall recapitulation using the PLIBEL Checklist method, the value of theoperator cutting was $66.66 \%$ while the finishing operator was $44.44 \%$. In themethod, the Quick Exposure Check greatest risk recapitulation on the back, shoulders and wrists is $72.15 \%$ for the cutting operator, while the finishing operator is $55.11 \%$ so that from the results of the recapitulation there needs to be an improvement in the work station of each operator. This shows the need to hold further research and make changes to the work station. From the calculation of the Exposure Scor, it can also be seen that the values for the back and wrists are at the High level, which means that the risk of injury is very high, this is due to the lack of work support tools in accordance with the needs of each operator. Supporting tools such as work desks and chairs are expected to minimize the risk of muscle injury. In addition, this proposal can also improve the performance of operators. The repair design is in the form of a work facility design, namely the operator's desk and the operator's chair using the CATIA image application.
\end{abstract}

Keyword : Plibel Checklis; QEC ; Ergonomi; Antropometri

\begin{abstract}
Abstrak
PT Karsa Wijaya Pratama merupakan industri yang bergerak pada bidang otomotif beberapa aktivitas yang dilakukan menggunakan mesin produksi yang manual, Berdasarkan pengamatan permasalahan yang timbul pada perusahaan tersebut yang menyebabkan resiko pada pekerjaan disebabkan postur tubuh pekerja yang tidak sesuai dengan standar untuk itu tujuan dari penelitian ini agar pekerja dapat bekerja dengan sesuai agar tidak mengalami cidera pada otot dalam jangka panjang atau pendek. Penelitian diawali dengan mengetahui permasalahan dan menilai postur kerja dengan kuisioner PLIBEL Checklist dan Quick Exposure Check (QEC). Berdasarkan hasil rekapitulasi keseluruhan dengan metode PLIBEL Checklist nilai pada operator cutting sebesar 66,66\% sedangan pada operator Finishing sebesar 44,44\%. Pada metode Quick Exposure Check rekapitulasi resiko terbesar pada bagian punggung, bahu dan pergelangan tangan sebesar $72,15 \%$ untuk operator cutting, sedangkan operator finishing sebesar $55,11 \%$ sehingga dari
\end{abstract}


hasil rekapitulasi perlu adanya perbaikan pada stasiun kerja masing-masing operator. Hal ini menunjukan perlu diadakan nya penelitian lebih lanjut dan dilakukan suatu perubahan pada stasiun kerja tersebut. Dari perhitungan Exposure Scor juga dapat dilihat bahwa nilai untuk punggung dan pergelangan tangan yang berada pada level High yang berarti resiko terjadinya cidera sangat tinggam hal tersebut disebabkan karna kurang nya alat penunjang kerja yang sesuai dengan kebutuhan dari masing-masing operator Untuk itu perlu nya usulan berupa alat penunjang seperti meja kerja dan kursi kerja sehingga diharapkan dapat meminnimalisir resiko cedera otot. Selain itu usulan ini juga dapat meningkatkan kinerja dari para operator. Rancangan perbaikan berupa rancangan fasilitas kerja, yaitu meja kerja operator dan kursi kerja operator dengan menggunakan aplikasi gambar CATIA.

Kata kunci: Plibel Checklis; QEC ; Ergonomi; Antropometri

\section{Pendahuluan}

Perkembangan dunia industri di Indonesia yang semakin maju telah menimbulkan persaingan yang semakin ketat antar perusahaan dalam bidang industri. Ringkas kata kemajuan teknologi saat ini benar-benar telah diakui dan dirasakan memberikan banyak kemudahan dan kenyamanan bagi kehidupan umat manusia (Dwiningrum \& Purbani, 2012). Oleh karena itu masyarakat Indonesia perlu mempersiapkan diri agar tidak tertinggal oleh negara-negara lain misalnya dalam hal manufactur. Hal ini disebabkan semakin pesatnya dunia industri dan banyak upaya inovatif untuk meningkatkan kualitas laporan keuangan baik yang menyangkut sumber daya manusia dan mesin. Hukum ergonomi dapat didefinisikan sebagai studi tentang aspek-aspek manusia dalam lingkungan kerjanya dan akan mempelajari keterbatasan dari kemampuan manusia dalam berinteraksi serta mempelajari peralatan atau perangkat buatan (Sholihah \& Anward, 2012), Untuk itu ergonomi dibutuhkan studi tentang sistem dimana manusia, fasilitas kerja dan lingkungannya saling berinteraksi dengan tujuan utama yaitu menyesuaikan suasan kerja dengan manusianya (Nurmianto, 2008).

PT. Karsa Wijaya Pratama merupakan suatu perusahaan manufactur yang bergerak pada bidang otomotif yang memproduksi berbagai macam alat otomotif yang berlokasi didaerah Bekasi, Jawa Barat. (Iridiastadi et al., 2014) Perusahaan tersebut memiliki keunggulan dalam pembuatan alat-alat Cheking Fixture, perusahaan tersebut sudah berdiri sejak tahun 2005 dengan menggeluti bidang otomotif yang makin lama menjadi daya saing pada perusahaan industri otomotif lain nya. Didalam persaingan yang semakin pesat untuk itu PT. Karsa Wijaya Pratama menjamin kualitas terbaik kepada customer dengan menghasilkan produk yang sesuai dengan keinginan pelanggan. Berdasarkan pengamatan permasalahan yang timbul pada perusahaan tersebut yang menyebabkan resiko pada pekerjaan disebabkan postur tubuh pekerja yang tidak sesuai dengan standar, dikarenakan banyak yang melakukan pekerjaan yang tidak ergonomi, seperti operator membungkuk, operator jongkok. Aktivitas operatorpun masih dilakukan secara manual dengan gerakan yang sama dan dalam jangka waktu yang lama dapat menimbulkan kelelahan serta dapat menyebabkan keluhan pada sistem muskuloskeletal, hal tersebut dapat menjadi dampak pada jalan nya produksi. (Audina, 2019) Untuk itu dari permasalahan yang ada data yang digunakan untuk menentukan 
titik permasalahan tersebut menggunakan data cidera pada kerja yang diperoleh dari pekerjanya

Tabel I. Data Permasalahan di Perusahaan

\begin{tabular}{|l|c|c|c|c|c|c|}
\hline $\begin{array}{l}\text { Periode } 1 \\
\text { Tahun }\end{array}$ & $\begin{array}{l}\text { Operator } \\
\text { Drafting }\end{array}$ & $\begin{array}{l}\text { Operator } \\
\text { Cutting }\end{array}$ & $\begin{array}{l}\text { Operator } \\
\text { Machining }\end{array}$ & $\begin{array}{c}\text { Operator } \\
\text { Painting }\end{array}$ & $\begin{array}{l}\text { Operator } \\
\text { Finishing }\end{array}$ & $\begin{array}{c}\text { Operator } \\
\text { Assembling }\end{array}$ \\
\hline Cidera Ringan & 4 & 2 & 2 & 3 & 2 & 8 \\
\hline Cidera Berat & 0 & 11 & 0 & 0 & 7 & 0 \\
\hline
\end{tabular}

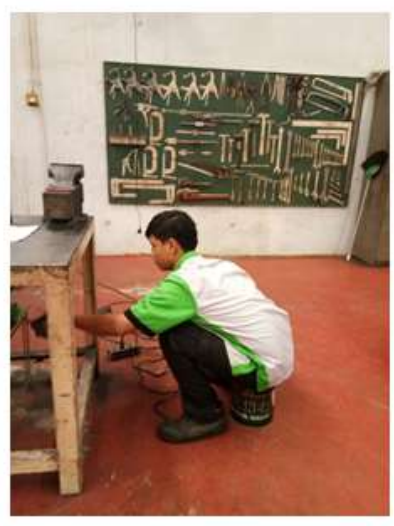

Operator Finishing

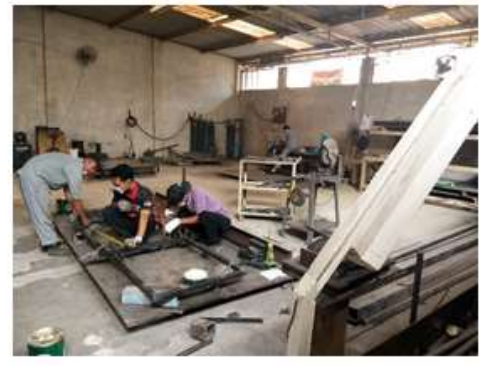

Operator Cutting

Sumber : PT Karsa Wijaya Pratam

Pada tabel I tersebut resiko ergonomi ini disebabkan oleh kurangnya alat penunjang kerja yang tidak sesuai dengan postur operator saat bekerja. Penanganan yang tanggap dan tepat terhadap resiko ergonomi yang muncul harus dilakukan untuk menghindari dampak negatif yang dialami pekerja. Untuk itu harus adanya perbaikan pada stasiun kerja guna mengetahui resiko cidera pada otot rangka dan sistem Muskuloskeletal pada manusia menggunakan ilmu ergonomi. Pada beberapa operator mengalami suatu pekerjaan yang sangat beresiko karna prosedur kerja dan fasilitas kerja yang kurang ergonomis. Berdasarkan gambar diatas diketahui bahwa operator Cutting dan finishing bekerja tidak sesuai sehingga dapat mengakibatkan cedera pada operator dalam jangka panjang, untuk itu perlu adanya perbaikan atau usulan pada operator finishing berupa alat penunjang kerja seperti bangku dan kursi kerja untuk mengurangi resiko atau beban kerja si operator.

\section{Metode Penelitian}

a) Ergonomi

Ergonomi berasal dari bahasa yunani, yaitu ergon yang berarti "kerja" (work), pengertian kerja secara sempit ialah kegiatan untuk mendapatkan upah, dan pengertian secara luas ialah semua gerakan manusia meski tidak mendapatkan upah. Nomos yang artinya "hukum" (natural laws). Ergo (gerak/ kerja) yang nomos (alamiah) adalah gerakan yang efektif, efisien, aman, tidak menimbulkan kelelahan dan kecelakaan sesuai kemampuan tubuh tetapi mendapatkan hasil kerja yang lebih optimal. Oleh karena itu ergonomi memerlukan keseimbangan antara kemampuan 
tubuh dan tugas kerja. (Santoso, 2004). dalam Didalam ergonomi dibutuhkan studi tentang sistem dimana manusia, fasilitas kerja dan lingkungannya saling berinteraksi dengan tujuan utama, yaitu menyesuaikan suasana kerja dengan manusianya. Ergonomi disebut juga sebagai "Human Factors". Menurut (Santoso, 2004) dalam (Jameela et al., 2014), tujuan ergonomi adalah untuk meningkatkan produktivitas tenaga kerja pada suatu institusi atau organisasi.

b) Metode PLIBEL Checklist

PLIBEL adalah salah satu metode untuk mengidentifikasi fakto-faktor ketegangan musculoskeletal yang dapat menyebabkan dampak yang merugikan. Yang dirancang untuk memenuhi kebutuhan-kebutuhan seperti itu. PLIBEL sudah digunakan didalam beberapa penelitian ergonomi dan sebagai suatu alat dibidang pendidikan (Suryani \& Mufti, 2019). PLIBEL merupakan suatu alat Checklist yang sederhana untuk memeriksa penyebab utama resiko musculoskeletal serta hubungan nya dengan penilaian tempat kerja. Aspek waktu, lingkungan dan organisasi juga turut menjadi pertimbangan dalam metode ini sebagai faktor-faktor pengubah. Keuntungan PLIBEL antara lain :

1. Keuntungan PLIBEL adalah dapat mengamati bagian tubuh maupun keseluruhan tubuh dan meringkas identifikasi resiko ergonomi yang terjadi dalam beberapa kalimat. Selain itu PLIBEL adalah suatu metode investigasi awal untuk petinjau tempat kerja dalam mengidentifikasi resiko ergonomi, dan dapat juga dilampirkan dengan pengukuran yang lain seperti beban dan waktu atau pengamatan dari peneliti yang lain.

2. Kelemahan metode PLIBEL merupakan metodeyang sangat umum dan tidak dimaksudkan untuk pekerjaan khusus. Banyak metode lain yang digunakan untuk pekerjaan khusus atau bagian tubuh yang spesifik dan dapat mencatat jawaban yang lebih rinci. Jika perlu beberapa metode yang spesifik dapat digunakan sebagai bahan tambahan pada kuisioner PLIBEL.

Faktor-faktor penyebab tingginya risiko MSD adalah ketidaknyamanan desain fasilitas kerja pada stasiun pemasangan granito karena tidak adanya meja kerja, benda kerja pada stasiun pemasangan granito berada di bawah telapak kaki operator, sehingga siku, lengan, dan tangan harus bekerja lebih keras dibandingkan dengan menggunakan meja kerja yang ergonomis. Keluhan pada kaki disebabkan posisi jongkok yang menyebabkan kemiringan tidak wajar pada kaki, punggung dan leher operator juga membungkuk dan membengkok untuk meraih benda kerja dan menjaga keseimbangan, sehingga menyebabkan gangguan MSD pada leher bahu, dan punggung serta akibat posisi membungkuk, otot punggung bagian bawah akan tertarik dan dalam jangka waktu yang panjang akan menimbulkan permasalahan pada otot-otot tubuh lainnya.

c) Metode Quick Exposure Check (QEC) 
Quick Exposure Check (QEC) merupakan suatu metode untuk penilaian terhadap resiko kerja yang berhubungan dengan gangguan otot di tempat kerja. Metode ini menilai gangguan resiko yang terjadi pada bagian belakang punggung, bahu/lengan, pergelangan tangan, dan leher QEC membantu untuk mencegah terjadinya WMSD's seperti gerak repetitive, gaya tekan, postur yang salah, dan durasi kerja (Stanton et al., 2004). Konsep dasar dari metode ini adalah mengetahui seberapa besar exposure score untuk bagian tubuh tertentu yang dibandingkan dengan bagian tubuh lainnya. Exposure score dihitung untuk masing-masing bagian tubuh dengan mempertimbangkan \pm 5 kombinasi/ interaksi, misalnya postur dengan gaya/beban, pergerakan dengan gaya/beban, durasi dengan gaya/beban, postur dengan durasi, pergerakan dengan durasi Perhitungan Nilai Exposure Level Berdasarkan Metode Quick Exposure Check (QEC). $E(\%)=\frac{X}{X M A X} 100 \%$. Tujuan dari penggunaan QEC ini adalah:

1. Menilai perubahan paparan pada tubuh yang berisiko terjadinya muskuloskeletal sebelum dan sesudah intervensi ergonomi.

2. Melibatkan pengamat dan juga pekerja dalam melakukan penilaian dan mengidentifikasi kemungkinan untuk perubahan pada sistem kerja.

3. Membandingkan paparan risiko cedera diantara dua orang atau lebih yang melakukan pekerjaan yang sama, atau diantara orang-orang yang melakukan pekerjaan yang berbeda.

4. Meningkatkan kesadaran diantara para manajer, engineer, desainer, praktisi keselamatan dan kesehatan kerja dan para operator mengenai faktor risiko musculoskeletal pada stasiun kerja. Salah satu karakteristik yang penting dalam metode ini adalah penilaian dilakukan oleh peneliti/observer dan pekerja/worker, dimana faktor risiko yang ada dipertimbangkan dan digabungkan dalam implementasi dengan tabel skor yang ada (Li \& Buckle, 1999) sehingga memperkecil bias penilaian subjektif dari peneliti/observer.

Adapun kelebihan lain dari metode ini adalah:

1. Dapat digunakan untuk sebagian besar faktor risiko fisik dari MSDs.

2. Mempertimbangkan kebutuhan peneliti dan bisa digunakan oleh peneliti yang tidak berpengalaman.

3. Mempertimbangkan kombinasi dan interaksi berbagai faktor risiko di tempat kerja (multiple risk factors), baik yang bersifat fisik maupun psikososial.

4. Mudah dipelajari dan efektif untuk digunakan. Disamping berbagai keuntungan tersebut, metode ini memiliki beberapa kekurangan, diantaranya adalah:

a. Metode hanya fokus pada faktor fisik tempat kerja.

b. Pelatihan dan praktek tambahan diperlukan oleh penggunan yang belum berpengalaman untuk pengembangan reliabilitas pengukuran (Stanton et al., 2004). 


\section{Hasil dan Pembahasan}

\section{Perhitungan Metode PLIBEL Checklist}

Pada tahap awal Hasil dari pengolahan data PLIBEL Checklist diperoleh dari Kuisioner PLIBEL dan menghitung nilai presentase dari setiap bagian anggota tubuh yang menjadi variabel di metode ini. Nilai presentase didapatkan dengan cara menghitung hasil jumlah "Ya" pada masing-masing kolom jawaban pertanyaan yang telah diisi dan dijawab oleh setiap pekerja, kemudian membagi jawaban tersebut dengan total jumlah pertanyaan dan dikalikan 100\%. Pengamatan dengan metode PLIBEL untuk menentukan faktor-faktor penyebab cidera otot atau musculosceletal disorder sehingga dapat mengetahui kegiatan yang dilakukan pekerja memiliki faktor resiko atau tidak.

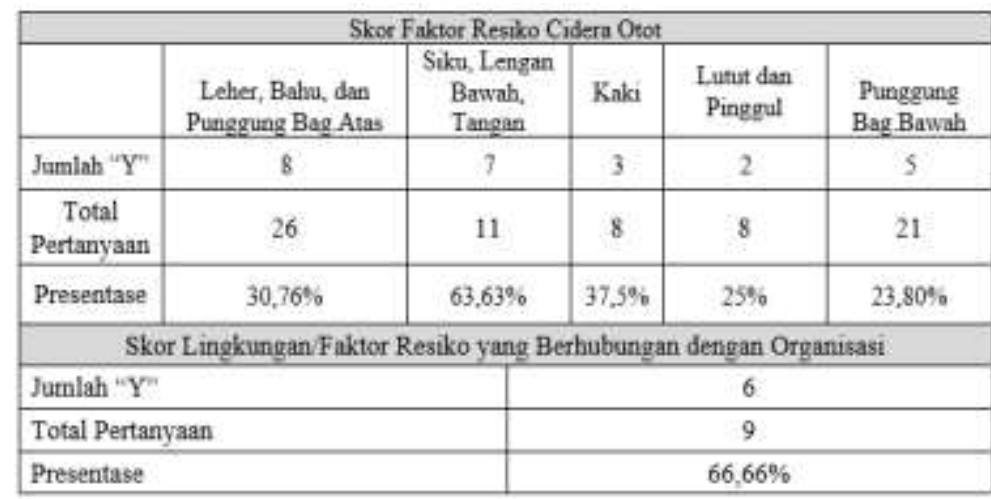

Gambar I. Perhitungan Metode PLIBEL Operator Cutting

Dari Hasil pengolahan data Pada Gambar I menyatakan bahwa nilai presentase yang dapat menyebabkan terjadinya resiko cedera pada otot dapat diketahui:

1. Hasil pengolahan data menyatakan bahwa bagian Siku, lengan bawah, Tangan memiliki resiko Musculosceletal Disorder dengan presentase paling tinggi atau paling besar yakni sebesar $63,66 \%$

2. Untuk presentasi tertinggi nomer 2 yakni pada bagian kaki dikarenakan presentase nya sebesar $37,5 \%$

3. Dan peringkat tertinggi berikutnya yaitu pada bagian Leher, Bahu, dan Punggung Bagian Atas dengan presentase sebesar 30,76\%

4. Skor pada faktor lingkungan termasuk kedalam presentase tertinggi dikarenakan presentase nya melebihi $50 \%$ yaitu sebesar $66,66 \%$ 


\begin{tabular}{|c|c|c|c|c|c|}
\hline & $\begin{array}{c}\text { Skor Faktor Resiko Cidera Otot } \\
\text { Punggung Bag.Atas }\end{array}$ & $\begin{array}{c}\text { Siku, Lengan } \\
\text { Bawah, } \\
\text { Tangan }\end{array}$ & Kaki & $\begin{array}{c}\text { Lutut dan } \\
\text { Pinggul }\end{array}$ & $\begin{array}{c}\text { Punggung } \\
\text { Bag.Bawah }\end{array}$ \\
\hline Jumlah "Y" & 11 & 8 & 4 & 4 & 7 \\
\hline $\begin{array}{c}\text { Total } \\
\text { Pertanyaan }\end{array}$ & 26 & 11 & 8 & 8 & 21 \\
\hline Presentase & $42,30 \%$ & $72,72 \%$ & $50 \%$ & $50 \%$ & $33,33 \%$ \\
\hline \multicolumn{7}{|c|}{ Skor Lingkungan/Faktor Resiko yang Berhubungan dengan Organisasi } \\
\hline Jumlah "Y" & \multicolumn{5}{|c|}{4} \\
\hline
\end{tabular}

Gambar II. Perhitungan Metode PLIBEL Operator Finishing

Dari Hasil pengolahan data Pada Gambar II menyatakan bahwa nilai presentase yang dapat menyebabkan terjadinya resiko cedera pada otot dapat diketahui:

1. Hasil pengolahan data menyatakan bahwa bagian Siku, lengan bawah, Tangan memiliki resiko Musculosceletal Disorder dengan presentase paling tinggi atau paling besar yakni sebesar $72,72 \%$

2. Untuk presentasi tertinggi nomer 2 yakni pada bagian Leher, Bahu, dan Punggung Bagian Atas dikarenakan presentase nya sebesar 42,30\%

3. Dan peringkat tertinggi berikutnya yaitu pada bagian Kaki dan Lutut, Pinggul dengan presentase sebesar $50 \%$

4. Skor pada faktor lingkungan termasuk kedalam presentase rendah dikarenakan presentase nya kurang dari 50\% yaitu sebesar 44,44\%

2. Perhitungan Metode Quick Exposure Check (QEC) 
Pengolahan data dalam penelitian ini menggunakan kuisioner pada operator produksi, dimana operator produksi mempunyai tingkat resiko tinggi dalam menjalankan pekerjaan. Proses pengumpulan data dilakukan melalui wawancara dan observasi. Proses wawancara dilakukan untuk memperoleh data QEC dari sudut pandang pekerja, sedangkan observasi dilakukan untuk memperoeh data QEC dari sudut pandang pengamat. Penilaian postur kerja dilakukan pada semua stasiun kerja di bagian konstruksi yang terdiri stasiun kerja Cutting dan Finishing. Sebelum dilakukan penilaian, maka perlu dilakukan rekapitulasi jawaban dari kuesioner

\begin{tabular}{|c|c|c|c|c|c|c|c|c|c|}
\hline No. & Stasiun Kerja & H & I & J & K & L & M & N & O \\
\hline 1 & Cutting Welding & H2 & I3 & J2 & K2 & L1 & M3 & N2 & O1 \\
\hline 2 & Finishing & H1 & I2 & J2 & K2 & L1 & M2 & N1 & O1 \\
\hline
\end{tabular}

operator dan pengamat terlebih dahulu. Hasil rekapitulasi jawaban operator akan ditampilkan pada tabel I dan rekapitulasi kuesioner pengamat akan ditampilkan pada gambar III

Gambar III. Rekapitulasi Kuisioner QEC Operator

Pada gambar III menunjukan rekapitulasi dari hasil kuisoner operator yang diambil berdasarkan kuisioner, hasil rekapitulasi jawaban pengamat di atas menunjukkan bahwa penilaian beban maksimum yang ditangani memperoleh nilai $\mathrm{H} 1$, hal ini menunjukkan bahwa beban yang ditangani ringan (5kg atau kurang) sedangkan untuk H2 menunjukan beban yang ditangani (6kg hingga 10kg). Nilai I2 menunjukan waktu pengerjaan (2 hingga 4jam) sedangkan I3 (lebih dari 4jam). Nilai J2 menunjukan bahwa kekuatan yang digunakan oleh satu tangan saat bekerja adalah rendah yaitu (1 hingga 4kg). Nilai K2 menunjukkan bahwa pekerjaan tersebut membutuhkan ketelitian yang tinggi. Nilai L1 menjelaskan saat bekerja, pekerja tidak menggunakan kendaraan. Nilai M2 menunjukan bahwa operator menggunakan alat yang menghasilkan getaran selama 1 jam hingga 4 jam/hari. Sedangkan M3 menjelaskan penggunaan peralatan yang bergetar dalam bekerja selama lebih dari 4 jam/hari. Nilai N1 menjelaskan operator tidak mengalami kesulitan saat melakukan pekerjaan sedangkan N2 operator terkadang mengalami kesulitan. Nilai O1 menjelaskan pada saat bekerja, operator (tidak mengalami stress). 


\begin{tabular}{|c|c|c|c|c|c|c|c|c|}
\hline \multirow[t]{2}{*}{ No } & \multirow[t]{2}{*}{ Stasiun Kerja } & \multicolumn{2}{|c|}{ Punggung } & \multicolumn{2}{|c|}{ Bahu/Lengan } & \multicolumn{2}{|c|}{$\begin{array}{c}\text { Pergelangan } \\
\text { Tangan }\end{array}$} & \multirow{2}{*}{$\begin{array}{c}\text { Leher } \\
\text { G }\end{array}$} \\
\hline & & $\mathrm{A}$ & B & $\mathrm{C}$ & $\mathrm{D}$ & $E$ & $\mathrm{~F}$ & \\
\hline 1 & Cutting Welding & $\mathrm{A} 3$ & B2 & $\mathrm{C} 1$ & D2 & E2 & F1 & G2 \\
\hline 2 & Finishing & $\overline{\mathrm{A} 2}$ & $\bar{B} 2$ & $\mathrm{C} 1$ & D2 & E2 & F2 & G2 \\
\hline
\end{tabular}

Gambar IV. Rekapitulasi Kuisioner QEC Pengamat

Berdasarkan hasil rekapitulasi jawaban kuesioner pengamat pada gambar VI menunjukkan bahwa hasil penilaian postur kerja yang berbeda-beda untuk setiap stasiun kerja. Dijelaskan bahwa pada penilaian bagian punggung, A2 menunjukkan punggung dalam posisi membungkuk atau memutar kesamping dengan sudut $20^{\circ}-60^{\circ}$ sedangkan A3 (terlalu memutar atau membungkuk). Nilai B2 menunjukkan pekerjaan yang dilakukan dengan duduk atau berdiri statis dalam waktu yang lama. Nilai C1 menunjukkan bahwa pada saat melakukan pekerjaan, posisi tangan berada disekitar pinggang atau lebih rendah. Nilai D2 merupakan durasi pergerakan bahu/lengan yang sering (pergerakan bisa berhenti sesaat/istirahat). Nilai E2 menunjukkan pergelangan tangan yang ditekuk. Nilai F1 menunjukkan pergerakan pergelangan tangan dengan pengulangan sebanyak 10 kali atau kurang/menit, sedangkan F2 (pergerakan pergelangan tangan dengan pengulangan sebanyak 10-20kali). G2 menunjukkan posisi leher yang terkadang tertekuk atau berputar.

a. Berikut ini merupakan hasil dari perhitungan nilai pada Tabel Exposure Score untuk operator 1 yaitu Cutting. Berdasarkan gambar dibawah nilai Dari tabel perhitungan bisa dilihat pada Gambar V diperoleh dengan menjumlahkan skor pada masingmasing bagian yang dinilai. Pada operator cutting bagian Punggung memperoleh skor terbesar yaitu 34, pada skor bahu yaitu 30, skor pergelangan tangan yaitu 32, skor leher yaitu 16, skor pengemudi yaitu 1, skor getaran yaitu 9, skor kecepatan yaitu 4 dan skor stress 1. Sehingga Total Exposure Score operator spindel adalah 127. 


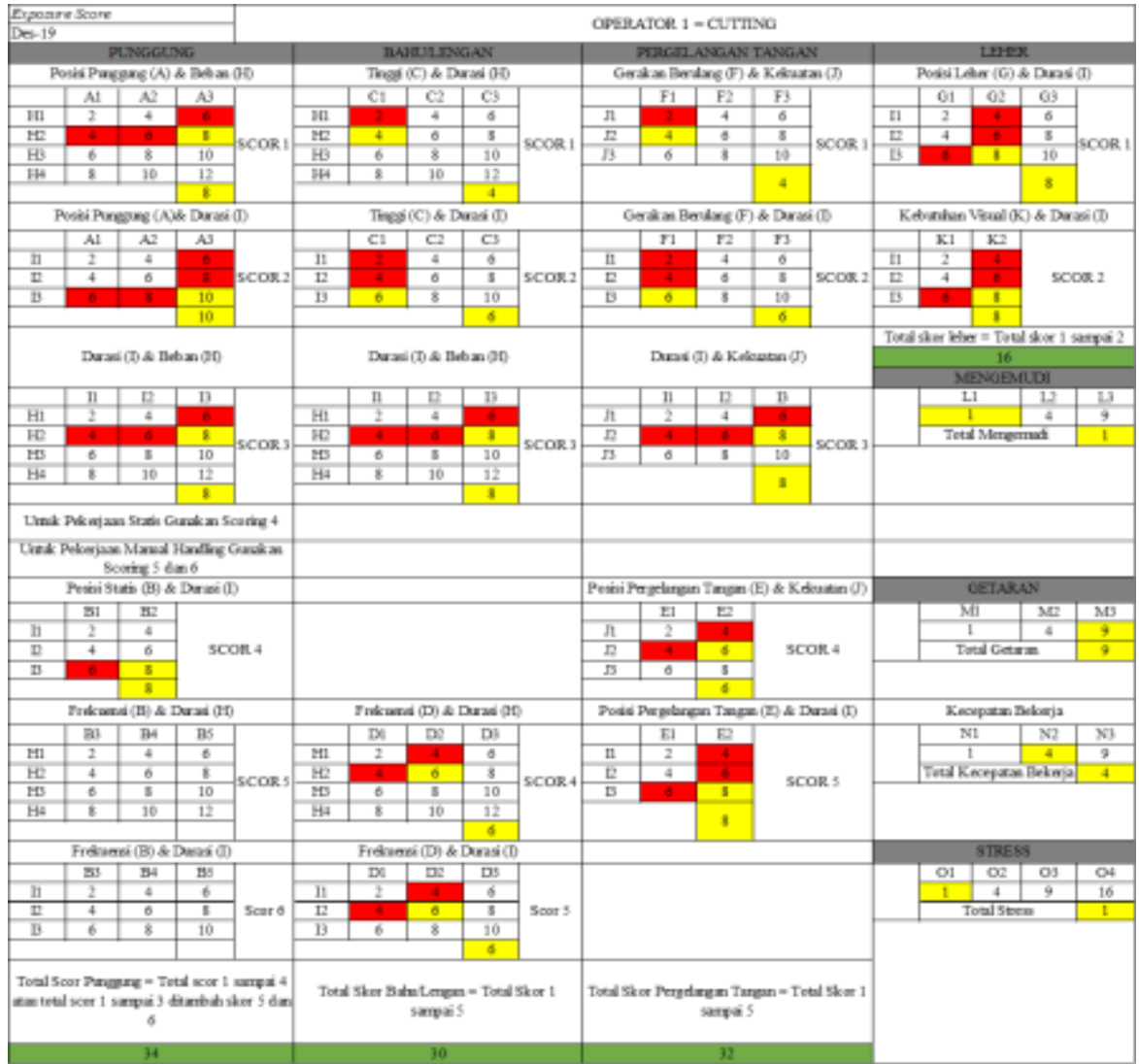

Gambar V Exposure Scor Operator Cutting

b. Perhitungan berdasarkan Tabel Exposure Scor Operator 2 Finishing, hasil dari perhitungan nilai pada Tabel Exposure Score untuk operator 1 yaitu Finishing. Berdasarkan gambar dibawah nilai Dari tabel perhitungan bisa dilihat pada Gambar VI diperoleh dengan menjumlahkan skor pada masing-masing bagian yang dinilai. Pada operator cutting bagian Punggung memperoleh skor terbesar yaitu 24, pada skor bahu yaitu 26, skor pergelangan tangan yaitu 30, skor leher yaitu 10 , skor pengemudi yaitu 1 , skor getaran yaitu 4, skor kecepatan yaitu 1 dan skor stress 1. Sehingga Total Exposure Score operator spindel adalah 97 
Putri Pertiwi, Zeny Fatimah Hunusalela

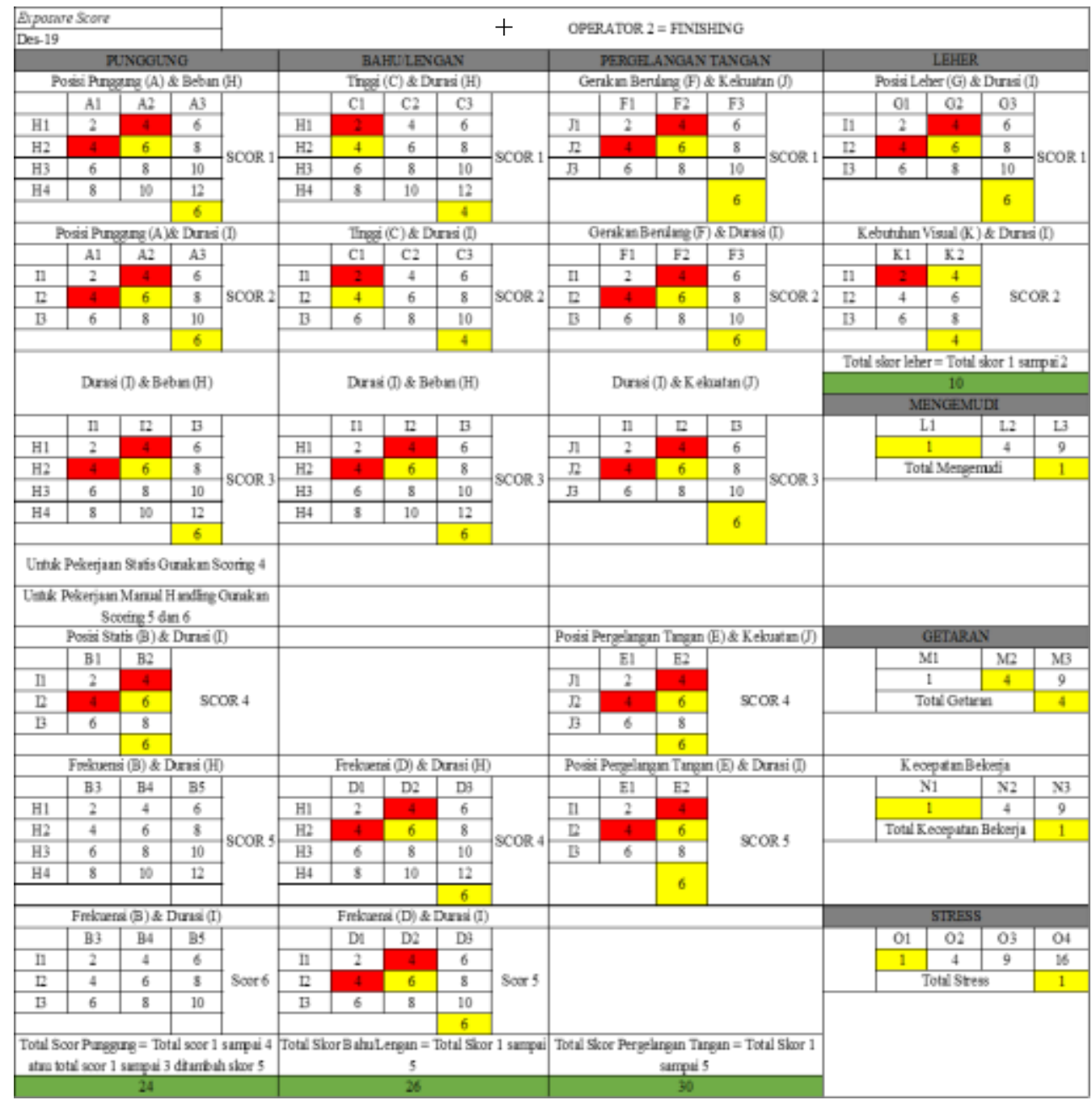

Gambar VI Exposure Scor Operator Finishing

Dari hasil perhitungan diatas untuk nilai resiko pada operator Cutting sebesar $72,15 \%$ untuk itu perlu adanya tindakan yang lebih lanjut sedangkan hasil perhitungan diatas untuk nilai resiko pada operator finishing sebesar 55,11\% untuk itu perlu adanya tindakan yang lebih lanjut.

\begin{tabular}{|c|c|c|c|c|}
\hline Stasin Kerja & Operator & $\begin{array}{c}\text { Nilai Exposure } \\
\text { Level }\end{array}$ & Rata-Rata Exposure & Action Level Resiko \\
\hline Cutting & 1 & $72,15 \%$ & & $\begin{array}{c}\text { Perlu Penelitian Lebih lanjut } \\
\text { dan Perlu adariya Perbaikan }\end{array}$ \\
\cline { 1 - 1 } \cline { 5 - 5 } Fimishing & 2 & $55,11 \%$ & $63,63 \%$ & $\begin{array}{c}\text { Perlu Penelitian Lebih lanjut } \\
\text { dan Perlu adariya Perbaikan }\end{array}$ \\
\hline
\end{tabular}

Gambar VII Rekapitulasi hasil Exposure Score 
Dari hasil pembahasam Rekapitulasi Exposure Scor level diatas yang ditunjukan pada gambar VII terdapat hasil persentase sebesar $72,15 \%$ pada operator Cutting, sedangkan 55,11\% pada operator Finishing untuk presentase rata-rata dari kedua nya sebesar $63,63 \%$. Hal ini menunjukan perlu diadakan nya penelitian lebih lanjut dan dilakukan suatu perubahan pada stasiun kerja tersebut
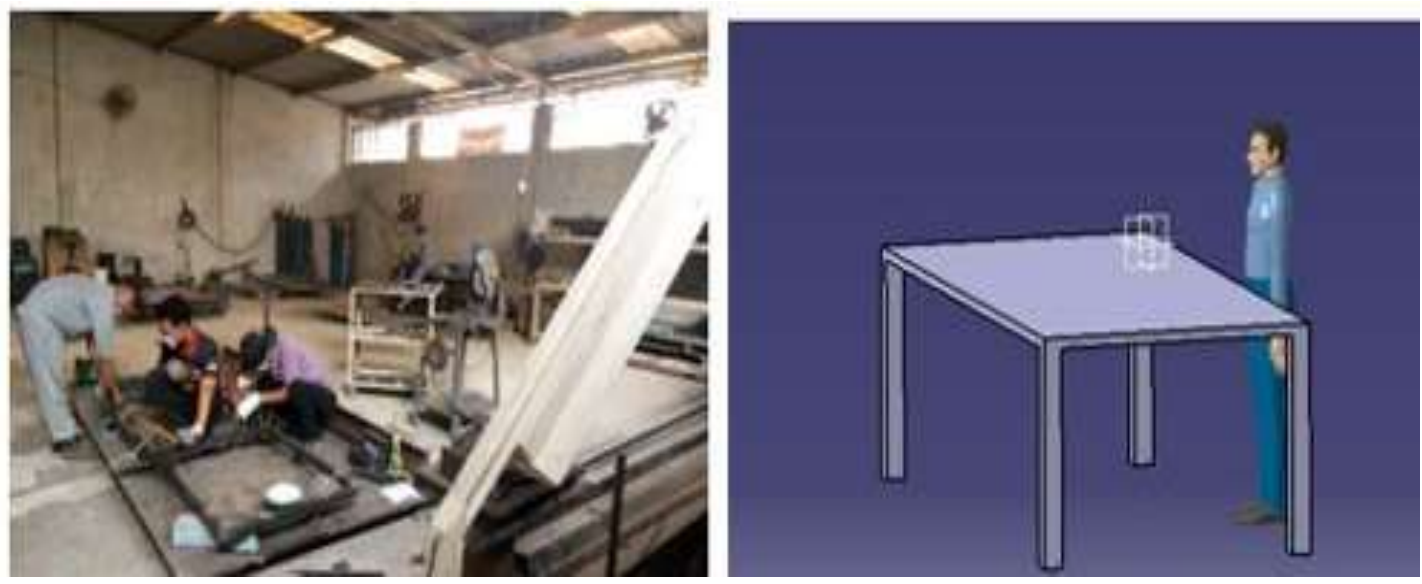

Gambar VIII Rancangan Usulan Operator Cutting

Perancangan Usulan meja kerja pada operator cutting yang tercantum pada gambar VII didesain sesuai kebutuhan operator dilihat dari postur tubuh operator dengan tujuan ketika operator melakukan proses cutting operator tidak perlu membungkuk dan jongkok hal tersebut dapat menyebabkan resiko cedera. Usulan perbaikan tersebut agar nilai exposure level semakin kecil, semakin kecil nilai exposure level maka semakin kecil resiko cedera, terlihat rancangan meja operator Cutting dari tampak belakang. Untuk bahan yang digunakan dalam pembuatan meja kerja adalah baja dengan ketebalan $18 \mathrm{~mm}$ dengan tinggi $100 \mathrm{~cm}$ panjang $240 \mathrm{~cm}$ dan lebar $140 \mathrm{~cm}$. Ukuran dimensi meja kerja Operator cutting yang digunakan saat ini didapatkan dengan melakukan pengukuran secara langsung.
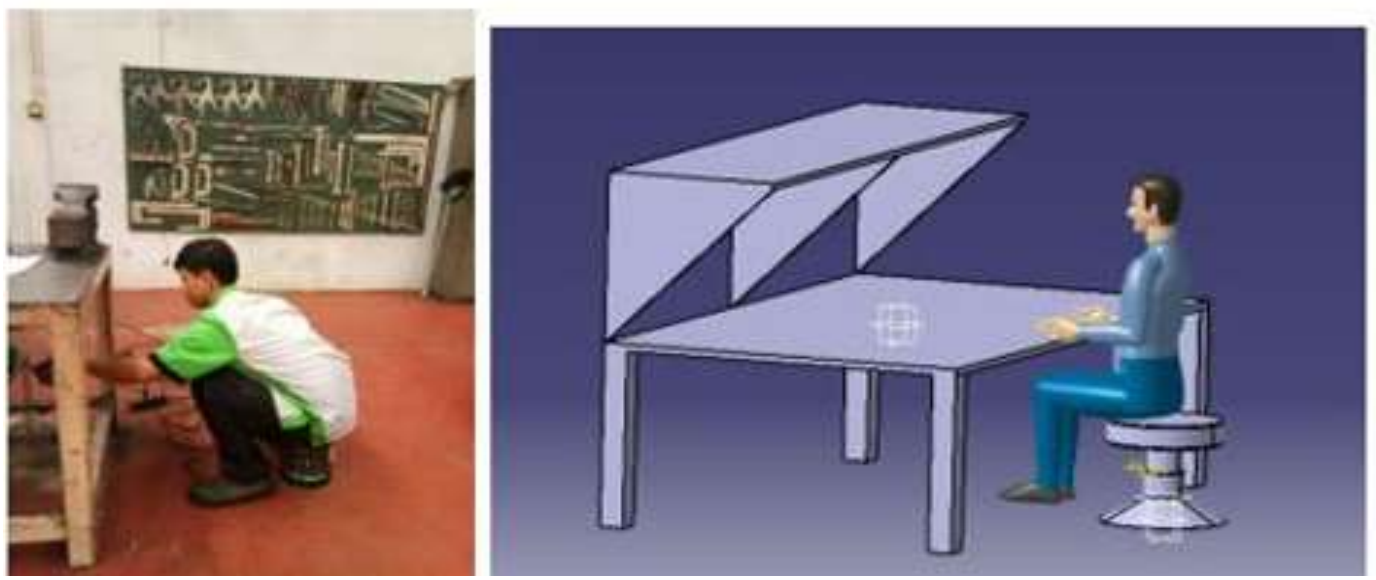

Gambar IX Rancangan Usulan Operator Finishing 
Rancangan Usulan ke 2 berupa meja dan kusi kerja pada operator cutting yang tercantum pada gambar 4.13 didesain sesuai kebutuhan operator dilihat dari postur tubuh operator dengan tujuan ketika operator melakukan proses finishing operator tidak perlu jongkok hal tersebut dapat menyebabkan resiko cedera. Usulan perbaikan tersebut agar nilai exposure level semakin kecil, semakin kecil nilai exposure level maka semakin kecil resiko cedera, terlihat rancangan meja operator Finishing dari tampak samping. Untuk bahan yang digunakan dalam pembuatan meja kerja adalah baja dengan ketebalan $10 \mathrm{~mm}$ dengan tinggi $67 \mathrm{~cm}$ panjang $100 \mathrm{~cm}$ dan lebar $50 \mathrm{~cm}$, untuk kursi operator diameter 46 dengan panjang kursi $60 \mathrm{~cm}$ kursi dirancang dapat disesuaikan ukuran nya. Ukuran dimensi meja kerja dan kursi Operator Finishing yang digunakan saat ini didapatkan dengan melakukan pengukuran secara langsung.

\section{Kesimpulan}

Berdasarkan hasil penelitian yang telah dilakukan, maka diperoleh suatu kesimpulan yaitu:

1. Berdasarkan hasil Penelitian menggunakan Metode Plibel dan Quick Exposure Check diperoleh hasil penyebab resiko yang terjadi pada masing-masing operator yang tidak sesuai dapat mengakibatkan cedera pada bagian Punggung, Bahu, Leher hingga Pergelangan Tangan. Dengan perhitungan menggunakan metode Metode Plibel dan Quick Exposure Check menemukan Tingkat presentase yang tinggi pada masing-masing operator sebesar $72,15 \%$ pada operator Cutting, sedangkan $55,11 \%$ pada operator Finishing. Presentase rata-rata dari kedua nya sebesar 63,63\%. dan perlu ada nya perbaikan berupa rancangan alat penunjang kerja agar operator dapat bekerja dengan baik dan nyaman .

2. Rancangan yang digunakan untuk operator Cutting merupa meja kerja opeartor yang mempunyai ketebalan $18 \mathrm{~mm}$ dengan tinggi $100 \mathrm{~cm}$ panjang $240 \mathrm{~cm}$ dan lebar $140 \mathrm{~cm}$ sesuai dengan kebutuhan masing-masing operator. Sedangankan untuk Operator Finishing merancang meja dan kursi dengan ketebalan $10 \mathrm{~mm}$ dengan tinggi $67 \mathrm{~cm}$ panjang $100 \mathrm{~cm}$ dan lebar $50 \mathrm{~cm}$ untuk rancangan Meja, untuk rancangan Kursi mempunyai panjang kursi $60 \mathrm{~cm}$ dengan diameter 46 sesuai dengan kebutuhan operator masing-masing. Semua rancangan yang dirancang berdasarkan ukuran tubuh operator yang dihitung menggunakan Antropometri dengan persentil 50. 


\section{Bibliografi}

Audina, D. W. (2019). PERANCANGAN TROLLEY SUPPLY CUTTING PADA PROSES MANUFAKTUR OTOMOTIF DENGAN PENDEKATAN PRINSIP ERGONOMI. President University.

Dwiningrum, S. I. A., \& Purbani, W. (2012). Manusia berkarakter dalam perspektif guru dan siswa. Jurnal Kependidikan: Penelitian Inovasi Pembelajaran, 42(1).

Iridiastadi, H., MSIE, P. D., \& Yassierli, P. D. (2014). Ergonomi suatu pengantar. Bandung: PT. Remaja Rosdakarya.

Jameela, H., Sugiharto, A. N., \& Soegianto, A. (2014). Keragaman genetik dan heritabilitas karakter komponen hasil pada populasi F2 buncis (Phaseolus vulgaris L.) hasil persilangan varietas introduksi dengan varietas lokal. Jurnal Produksi Tanaman, 2(4).

Li, G., \& Buckle, P. (1999). Current techniques for assessing physical exposure to work-related musculoskeletal risks, with emphasis on posture-based methods. Ergonomics, 42(5), 674-695.

Nurmianto, E. (2008). Ergonomic intervention in handicraft producing operation. 9th Asia Pasific Industrial Engineering \& Management System, Bali, Indonesia, 10081011.

Santoso, G. (2004). Ergonomi manusia, peralatan dan lingkungan. Jakarta: Prestasi Pustaka.

Sholihah, Q., \& Anward, H. H. (2012). Textbook ergonomics and human factors (basic concepts). Banjarmasin, P3Al Lambung Mangkurat University in Cooperation with Nusa Media Bandung.

Stanton, N. A., Hedge, A., Brookhuis, K., Salas, E., \& Hendrick, H. W. (2004). Quick exposure checklist (QEC) for the assessment of workplace risks for work-related musculoskeletal disorders (WMSDs). In Handbook of human factors and ergonomics methods (pp. 74-85). CRC Press.

Suryani, E., \& Mufti, D. (2019). PERBAIKAN STASIUN KERJA PADA PEMBUATAN SOFA DI CV. GEMILANG. ABSTRACT OF UNDERGRADUATE RESEARCH, FACULTY OF INDUSTRIAL TECHNOLOGY, BUNG HATTA UNIVERSITY, 13(3). 